How Do Gender Norms and Childcare Costs Affect Maternal Employment Across U.S.

States?

\author{
Leah Ruppanner \\ University of Melbourne \\ Caitlyn Collins \\ Washington University in St. Louis \\ Liana Christin Landivar \\ Women's Bureau, U.S. Department of Labor \\ Maryland Population Research Center \\ William J. Scarborough \\ University of North Texas
}

Published in Gender \& Society

Ruppanner, Leah, Caitlyn Collins, Liana Christin Landivar, and William J. Scarborough. 2021. "Norms, Childcare Costs, and Maternal Employment." Gender \& Society. Online first September 27. DOI: https://doi.org/10.1177/08912432211046988

\title{
Authors' Note:
}

The authors thank the Gender \& Society Deputy Editor, Sheryl Skaggs, and anonymous reviewers for their feedback on this manuscript. Some of the data used in this article are derived from Sensitive Data Files of the General Social Survey (GSS), obtained under special contractual arrangements designed to protect the anonymity of respondents. These data are not available from the authors. Persons interested in obtaining GSS Sensitive Data Files should contact the GSS at GSS @ NORC.org. All authors contributed equally to this manuscript. Views are those of the authors and not necessarily those of the U.S. Department of Labor.

Keywords: gender; mothers; employment; childcare; culture 
How Do Gender Norms and Childcare Costs Affect Maternal Employment Across U.S. States?

\begin{abstract}
In this article we investigate how state-to-state differences in U.S. childcare costs and gender norms are associated with maternal employment. Although an abundance of research has examined factors that influence mothers' employment, few studies explore the interrelationship between maternal employment and culture, policy, and individual resources across U.S. states. Using a representative sample of women in the 2017 American Community Survey along with state-level measures of childcare costs and gender norms, we examine the relationship between these state conditions and mothers' probability of employment. We pay careful attention to differences in mothers' level of education. Our results suggest that expensive childcare is associated with lower maternal employment, particularly for those with less education. For the college educated, expensive childcare is negatively associated with maternal employment in states with traditional gender norms that uphold mothers as primary caregivers. Among mothers with lower levels of education, gender norms have a limited association with employment. These findings suggest that highly educated mothers mobilize resources to remain in the labor force when paid work is supported by local gender norms. For less-educated mothers, expensive childcare predicts lower employment regardless of gender norms, indicating that structural constraints outweigh normative expectations among those with fewer resources.
\end{abstract}




\section{How Do Gender Norms and Childcare Costs Affect Maternal Employment Across U.S.}

\section{States?}

Two-thirds of women with children work outside the home in the United States (U.S. Bureau of Labor Statistics 2021), but maternal employment has stagnated in recent years (Women's Bureau, U.S. Department of Labor 2020). Mothers' labor force participation rates continue to vary by U.S. state, regional context, and individual resources (Ruppanner 2020). A wealth of research has explored the individual, cultural, and structural factors that shape mothers' employment (Blackburn, Bloom, and Neumark 1993; Collins 2019; Damaske 2011; Dean, Marsh, and Landry 2013; Jacobs and Gerson 2016; Landivar 2017). Importantly, though, few studies evaluate the interrelationship among these factors, a critical contribution because mothers' employment is influenced not just by culture, or policy, or individual resources, but by the interactions among them (Budig, Misra, and Boeckmann 2012; Padamsee 2009; PfauEffinger 2012).

We examine how women's educational attainment (an individual level resource), gendered family norms (a cultural condition), and state-level childcare costs (a structural constraint) are associated with maternal employment across U.S. states. At the individual level, scholars invoke theories of human capital and gender socialization to explain variation in maternal employment levels (Blackburn, Bloom, and Neumark 1993; Jacobs and Gerson 2016). At the structural level, workplace and market constraints such as discrimination in access to quality work, pay, and promotions, lack of workplace flexibility and benefits, and high out-ofpocket childcare costs act as barriers to maternal employment (Damaske 2011; Landivar 2017; Ruppanner, Moller, and Sayer 2019). But not all mothers face the same barriers to paid work. Those with higher levels of educational attainment have more resources to mitigate these 
challenges and maintain employment following childbirth (Hook and Paek 2020). Yet gendered norms of intensive mothering (Hays 1996) and the ideal worker (Acker 1990; Blair-Loy 2003) may exert a greater influence on college-educated mothers' decisions and options to remain employed (Stone 2007).

The cultural mandates implied in intensive mothering ideology encourage mothers to prioritize the welfare and development of their children over their own personal needs, desires, and job aspirations. Scholars have documented the expectation that mothers "put their children's needs first, and invest much of their time, labor, emotion, intellect and money in their children" (Hays 1996, 8). Even as support for women's employment has increased steadily, traditional cultural beliefs persist about mothers' primary responsibility for childrearing (Dernberger and Pepin 2020; Scarborough, Sin, and Risman 2019), leading U.S. working mothers to report substantial guilt and work-family conflict (Collins 2020). In the United States, cultural norms about the gendered division of household labor vary across regions and states, meaning that mothers face different normative pressures based on their place of residence (Charles, Guryan, and Pan 2018; Ruppanner and Maume 2016; Scarborough and Sin 2020).

Complicating matters further is the rising cost of childcare, which has major implications for maternal employment (Laughlin 2013). Cultural norms of intensive mothering and resulting unequal caregiving responsibilities create expectations that mothers need to earn enough to cover the cost of care to remain employed. This contributes to greater reductions in maternal employment (Landivar 2017), particularly when childcare is expensive and absorbs a large share of mothers' income (Chaudry et al. 2017). The costs of care and childcare provisions that reduce these costs, such as subsidies or Head Start programs, vary dramatically in their availability across states (Chaudry et al. 2017; Ruppanner 2020). These differences are consequential 
(Landivar, Ruppanner, and Scarborough 2021). Variation across states in childcare costs and access to childcare benefits, as well as differing predominant gender norms, means that parents face different realities in combining work and caregiving responsibilities based on their state of residence.

In this study we examine the interrelationship among individual-level resources, normative contexts, and structural childcare constraints in shaping maternal employment across the United States. We make three contributions. First, although a great deal of research documents cross-national differences in maternal employment, here we highlight state differences in childcare costs and gendered parenting norms to illustrate within-country variation in these contextual factors. Second, we attach state-level characteristics to a large representative sample of women from the 2017 American Community Survey (ACS) to test the association of childcare costs, gender norms, and their interrelation with mothers' employment. Third, we consider the role of individual resources in mitigating structural barriers to employment, examining these relationships by mothers' level of education.

Our results show that expensive childcare is associated with lower maternal employment, primarily among mothers with lower levels of education. Less-educated mothers in states with expensive childcare are nearly eight times less likely to be employed than those in states with lower childcare costs. Among college-educated mothers, the negative relationship between expensive childcare and employment is observed only in states with traditional gender norms conveying expectations that mothers should be primarily responsible for caregiving. When gender norms support the equal participation of mothers and fathers in caregiving, collegeeducated mothers' employment is unrelated to childcare costs. These findings suggest that highly educated mothers mobilize resources to remain in the labor force when paid work is supported 
by local gender norms. For less-educated mothers, expensive childcare costs predict lower employment regardless of gender norms, indicating that structural constraints outweigh normative expectations among those with few resources to overcome structural barriers.

\section{LIFEWORLDS OF MATERNAL EMPLOYMENT: INDIVIDUAL, CULTURAL, AND STRUCTURAL EXPLANATIONS}

Mothers make employment and caregiving decisions within particular environments that offer higher or lower support for combining work and family responsibilities. Collins (2019) identifies these environments - the constellation of barriers and opportunities arising from individual resources, cultural expectations, and organizational and national policies—as lifeworlds of motherhood. The interrelationship among individual, cultural, and structural resources and constraints shapes when, whether, and how much mothers work, as well as which mothers work. Attending to these various dimensions of mothers' lifeworlds is necessary to understand maternal employment patterns across the United States—not just what the patterns are, but how and why they differ by cultural and political context. We expect that childcare costs (a structural constraint) and gender norms (a cultural condition) will vary in their association with maternal employment depending on mothers' level of education (an individual resource).

\section{Childcare Costs as a Structural Constraint}

The United States relies on a market-based approach to childcare, characterized by minimal government intervention and financial provision only for families in the greatest need (Ruppanner 2020). As a result, childcare costs vary widely across states (see Figure 1). Centerbased infant childcare absorbs 15 percent of married couples' annual family income in New York, for example, but only 7 percent in Louisiana. To be affordable, the U.S. Department of 
Health and Human Services (2015) indicates that childcare costs should not exceed 7 percent of family income, but most families who pay for childcare surpass this threshold. In fact, nine states have average childcare costs that are more than double the recommended share.

[Figure 1 About Here]

In the absence of a government-supported national childcare infrastructure, families turn to the market or extended family to provide care. That childcare costs pose a major barrier to maternal employment is well established in the literature (Blau and Tekin 2007; Chaudry et al. 2017). Yet most research has focused on individual decision making or the impact of federal provisions for families near or below the poverty threshold (Connelly and Kimmel 2003; Tekin 2007). Considering state variation reveals that mothers face different constraints related to childcare costs depending on where they live. States' economic conditions and policies influence the cost of center-based childcare through differing costs of living, the supply and demand of childcare, and regulations guiding childcare operations (Chaudry et al. 2017). In addition, state policies may subsidize high childcare costs through investments in programs such as statefunded pre-K (pre-kindergarten) (Friedman-Krauss et al. 2018) or the expansion of federal programs such as Head Start (Scarborough et al. 2021). Yet the availability of these public options remains low and unevenly distributed, meaning that market-based childcare costs are the most salient structural aspect of state childcare contexts. From this research question, we form our first hypothesis:

H1: Mothers will be less likely to be employed in states with expensive childcare.

\section{Gendered Parenting Norms and Cultural Context}

Gender norms are shared standards regarding proper and improper social conduct for women and men, including cultural expectations about who can and should work for pay outside 
the home or care for children. Gender norms provide both the cultural logics individuals use when making decisions as well as the criteria used in evaluating other people's behavior (Correll et al. 2017). Importantly, gender norms are not individual-level characteristics, although they are often reflected in individuals' attitudes that align with local culture. Instead, gender norms are features of specific environments and vary across contexts (Pearse and Connell 2016). The experience of residing in a place with a particular set of gender norms can influence individuals to align their attitudes and behaviors with the cultural environment (Scarborough and Sin 2020). This has implications for parenting and employment, because norms conveying women as primarily responsible for childcare have persisted in the form of intensive mothering ideologies that emphasize "good mothering" as parent-provided and time-intensive. These cultural expectations are often in contradiction to women's paid employment (Blair-Loy 2003; Hays 1996).

Intensive mothering norms in the United States are rooted in white middle-/upper-class ideals of parenting (Dow 2019; Fox 2006). Nonetheless, they constitute powerful normative standards against which many mothers are held (Ishizuka 2019; Lamar, Forbes, and Capasso 2019). Gross and colleagues' (2014) study of working-class Ohio mothers, for example, uncovered the tremendous toll women experienced in their efforts to maintain employment while simultaneously adhering to social norms of intensive mothering. Black mothers have challenged the construction of work and family as conflicting roles; and given the legacy of slavery in the United States, Black mothers have also been excluded from separate sphere schemas (Collins 1994). At the same time, norms of intensive motherhood have also been used to disparage Black mothers and justify disinvestment in public services (Collins 2000; Ferguson 2003). Therefore, it 
is possible that gender norms, while rooted in white middle-class ideals, may nonetheless shape the employment outcomes of Black mothers.

Expectations around mothers' primary responsibility for childcare also vary geographically (Charles et al. 2018; Scarborough and Sin 2020). Figure 2 illustrates that gender norms around who should care for children vary across states. In states such as Utah, West Virginia, and Arkansas, women are viewed as primary caregivers, whereas gender-equal parenting is supported in states such as Massachusetts, Iowa, and Nevada. This state variation in gender norms suggests that mothers may face different normative pressures depending on where they live. Considering the diversity of cultural contexts, we examine how state-level gender norms predict the likelihood of mothers' employment:

H2: Mothers will be more likely to be employed in states with stronger norms of gender egalitarianism.

[Figure 2 About Here]

\section{The Interaction of State Structural and Cultural Conditions}

Cross-national research highlights the interrelation of cultural norms and policy conditions comparing European and/or OECD (Organisation for Economic Co-operation and Development) countries (Boeckmann, Misra, and Budig 2015; Collins 2019). Mothers are less likely to work and report larger earnings penalties in countries where traditional gender norms weaken the effectiveness of childcare and parental leave policy (Boeckmann, Misra, and Budig 2015; Budig, Misra, and Boeckmann 2012; Kaufman 2020). By contrast, mothers in countries with more generous job-protected leaves and normative support for mothers' employment are more likely to work and earn more. In this regard, the intersection of policies and norms play a 
critical role in structuring maternal employment decisions. Here, we extend these theoretical insights to U.S. states.

In the United States, where there are no universal childcare provisions, mothers navigate a different set of structural conditions than many European nations with more robust family supports. Most mothers in the United States rely on market options for childcare, which vary widely from state to state (Figure 1). In addition to these structural conditions, there is important heterogeneity within the United States in local gender norms. Charles, Guryan, and Pan (2018) find major differences at the state level, whereas Scarborough and Sin (2020) identified variation in gender norms across commuting zones. Here, we focus on states because they play an important role in childcare settings. State policies and economic conditions influence the cost of childcare, which creates barriers to maternal employment (Landivar, Ruppanner, and Scarborough 2021). In addition, state policies may mitigate rising childcare costs through investments in state-funded pre-K (Friedman-Krauss et al. 2018) or the expansion of federal programs such as Head Start (Scarborough et al. 2021).

[Figure 3 About Here]

State-level childcare costs and gender norms are imperfectly correlated $(r=0.38)$, meaning that many places with similar childcare costs have different gender norms. For example, the average cost of center-based childcare for infants is less than 9 percent of married couples' annual family income in Alabama and South Dakota, but in Alabama women are expected to do the majority of childcare, whereas in South Dakota norms are more egalitarian (Figure 3). Conversely, some states with similar gender norms have different childcare costs. New Jersey and Massachusetts are both states with egalitarian gender norms, but childcare costs are much higher in Massachusetts. Lower childcare costs may predict higher maternal employment rates 
only in states with more egalitarian gender norms. Conversely, egalitarian gender norms may support maternal employment, but to a lesser extent, in high-cost states where the structural barriers are greater. Thus, we derive the following hypothesis:

H3: The relationship of state childcare costs to mothers' employment will depend on state gender norms.

\section{Education-Based Differences in Maternal Employment}

State characteristics provide a context for patterns of maternal employment, but individual-level attributes such as education and social class influence the types of resources mothers have available when negotiating the competing demands of parenting and work. Damaske $(2011,6)$, for example, finds that structural pressures are felt differently by workingclass and middle-class women: "middle-class women choose whether or not to pursue a career, and working-class and minority women need to work at a paid job.” Landivar's (2017) study of occupational differences in maternal employment shows that college-educated mothers have more workplace resources to maintain full-time employment and protect their career prospects. In part, this reflects education-based occupational sorting, with college-educated mothers more likely to be employed in professional occupations with greater access to paid leave and flexible schedules.

As these studies indicate, college-educated mothers are better equipped to tailor their employment because they have access to a wider range of economic and workplace resources. As a result, it is possible that these resources reduce highly educated mothers' structural barriers, such as high childcare costs, which may be more influential for less-educated mothers without sufficient income to cover these expenses. Reduced structural constraints, however, may lead to a greater influence of cultural norms among college-educated women to the extent that middle- 
class ideals of intensive mothering are most pronounced for this group (Damaske 2011; Stone 2007). Faced with expensive childcare costs, traditional gender norms may contribute to highly educated mothers' decisions to leave the labor force, even if they can feasibly afford childcare. Lower-educated mothers with fewer resources, on the other hand, may be less influenced by cultural norms because greater financial pressures crowd out this possibility. Considering these dynamics, we explore whether the relationship between state-level structural (childcare costs) and cultural (gender norms) features and maternal employment varies by mothers' educational attainment (individual resource). ${ }^{1}$

H4: The relationship of state context to maternal employment will vary by women's level of education.

\section{METHODS}

To test our research questions on the interrelationships between individual, structural, and cultural conditions and mothers' employment, we use both individual- and state-level data as well as analytical models suitable for the multilevel design of our research questions.

\section{Data and Variables}

Our individual-level data come from the 2017 American Community Survey (ACS) Public Use Microdata Series (Ruggles et al. 2020). We restrict our sample to women without children and mothers of preschool-age children (five years or younger) who are 25 through 50 years old. We omit those who are unemployed but seeking work because it is difficult to assess the role of childcare contexts for those who do not yet have a pressing need for it. We measure employment dichotomously (employed/not-employed) in all analyses. We also measure motherhood with a dichotomous variable indicating whether respondents have at least one child 
age five years or younger compared with those who have no children. Our results are consistent when we measure motherhood with a categorical variable comparing those without children with those who have one, two, or three or more young children (see Online Appendix Figure A1).

We use two additional sources to measure focal state characteristics. Childcare costs are measured as the cost of full-time, center-based childcare for infants as a percent of median family income for married couples in each state. Because childcare costs vary by age of the child, we use average costs for infant care to standardize comparisons between states. ${ }^{2}$ Information for this measure come from the Child Care Aware State Factsheets averaged from 2013 through 2017 (Child Care Aware 2013-2017). ${ }^{3}$

To measure state gender norms, we combined three attitudinal items $(\alpha=0.70)$ from the General Social Survey $(\mathrm{GSS})^{4}$ that are commonly used as measures of norms toward women's caregiving responsibilities (Cotter, Hermsen, and Vanneman 2011; Scarborough, Sin, and Risman 2019). These items are listed in Table $1 .{ }^{5}$ Because the GSS surveys about 1,000 to 2,000 respondents biennially, we pooled survey years from 2000 through 2018 to increase cell counts by state to produce reliable state-level estimates $(n=14,413)$. Following common approaches used in research on spatial variation in gender norms (Budig, Misra, and Boeckmann 2012; Knight and Brinton 2017), we aggregated individual-level survey responses to states. To adjust for potential differences between states in respondent sociodemographic characteristics as well as potential change over time in the pooled GSS data, we followed existing methods (Scarborough and Sin 2020) and used a varying intercept (by state) regression equation to obtain micro-adjusted state means for the measure of gender norms, accounting for respondent gender (women, men), race (White, Black, Hispanic, other), education (less than high school, high school diploma, some college, college degree or more), age, and survey year (measured 
categorically). In our resulting measure, higher scores indicate more egalitarian gender norms, conveying the belief that women and men should share equal family and work responsibilities, net of differences across these sociodemographic controls. We restricted our sample to states with at least 50 respondents represented in the GSS data used here. We removed Kansas from our analysis because this state was an outlier on our state-level measure of gender norms and had a large influence on model results. ${ }^{6}$ This resulted in a total inclusion of 43 states.

\section{[Table 1 About Here]}

After coding our focal state-level variables onto the individual-level data from the ACS, our final sample includes 291,900 respondents across 43 states. To explore differences in outcomes by education level, we compare women whose highest level of education is a high school diploma or less $(74,548$ respondents) with those with a college degree or more $(133,383$ respondents). We focus on these two levels of educational attainment because they offer analytical advantages in comparing the relationship of state childcare contexts to maternal employment between highly versus lower-educated mothers. Those with some college education are included in the pooled sample, but not analyzed independently. When focusing specifically on this group, we found that trends generally fell between high school- and college-educated mothers.

In addition to our focal variables, we also use several individual- and state-level control variables in our analytic models. At the individual level, we include race (Black, Hispanic, Asian, other, White), education (for pooled models using the full sample, measured categorically as less than high school or high school, some college, and college degree or more), marital status (married, separated/divorced, never married), age, age-squared, foreign-born status, logged hourly earnings, ${ }^{7}$ and logged spousal income. ${ }^{8}$ 
At the state level, we included a series of controls including casualization (percent working full time); industry composition (service to manufacturing employment ratio); unemployment rate; percent college educated; population size (logged); racial composition (percent White); and percent foreign born. We also included controls for three variables measuring the availability of public childcare programs: 1) the ratio of three-and four-year-olds in Head Start relative to the population of three- and four-year-olds in poverty, averaged from 2013 through 2017 (Kids Count Data Center 2021), ${ }^{9}$ 2) the share of eligible families receiving childcare subsidies in 2016 from the federal Child Care and Development Block Grant program (Ullrich, Schmit, and Cosse 2019), ${ }^{10}$ and 3) access to state-funded pre-K measured as the average percentage of three- and four-year-olds enrolled in these programs from 2013 through 2017 (National Institute for Early Education Research 2021). ${ }^{11}$

\section{Analytic Approach}

We examine the probability of employment for mothers relative to non-mothers, comparing those with a high school education or less with those who have a college degree. Although logistic regression models are conventionally used in predicting dichotomous outcomes such as employment, this practice presents challenges in studies using group comparisons. Many scholars argue that log odds and odds ratios calculated from logistic regression should not be used as coefficients for group comparisons because their scaling is contingent on each group's conditional distribution of the dependent variable (Long and Mustillo 2018). Alternative methods have been proposed to account for these challenges that focus on the marginal effects of predictors on the probability of the outcome, an approach that standardizes group comparisons using a common probability scale (Breen, Karlson, and Holm 2018). Here, we use linear probability models (LPM) because they offered the most efficient estimation 
strategy for our large sample using multiple group comparisons. ${ }^{12}$ In our application, coefficients are interpreted as the predicted difference in the probability of employment, allowing for direct comparisons by motherhood status and education.

Our baseline LPM is described in Equation 1:

$$
y_{i j}=\gamma_{00}+\beta_{1} m_{i j}+\beta_{2} c_{j}+\beta_{3} g_{j}+\lambda R_{i j}+\lambda S_{j}+U_{0 j}+U_{1 j} m_{i j}+\varepsilon_{i j}
$$

Here employment $\left(y_{i j}\right)$ is modeled as a function of the conditional average probability of employment $\left(\gamma_{00}\right)$, motherhood status $\left(m_{i j}\right)$, state childcare costs $\left(c_{j}\right)$, state gender norms $\left(g_{j}\right)$, as well as individual- $\left(R_{i j}\right)$ and state-level $\left(S_{j}\right)$ control variables. The coefficient for motherhood $\left(\beta_{1}\right)$ in these models represents the estimated difference between mothers and non-mothers in the probability of employment, with a negative coefficient reflecting that mothers are less likely to be employed than non-mothers. Equation 1 also includes a varying intercept and slope to account for the hierarchical structure of our data with respondents clustered within states that would otherwise violate the assumption of independence between observations. Specifically, state-level residuals from the intercept $\left(U_{0 j}\right)$ are parsed from the individual-level error term $\left(\varepsilon_{i j}\right)$ to effectively provide a separate intercept for each state. The model also separates state-level residuals from the effect of motherhood on employment $\left(U_{1 j} m_{i j}\right)$ to capture variability in the association of motherhood to employment across states.

To examine whether the relationship of motherhood to employment varies by state childcare costs and gender norms (testing $\mathrm{H} 1$ and $\mathrm{H} 2$ ), we add an interaction term to Equation 1 $\left[\beta_{4}\left(m_{i j} \times c_{j}\right)+\beta_{5}\left(m_{i j} \times g_{j}\right)\right]$. A three-way interaction is then added to examine whether the effects of childcare costs on mothers' likelihood of employment depend on state-level norms $\left[\beta_{6}\left(m_{i j} \times c_{j} \times g_{j}\right)\right]$, testing H3. To examine differences by women's level of education (H4), we 
run separate models for respondents with a high school education or less and those who are college educated. We divide differences between each group's coefficients by their joint standard errors to generate test statistics and associated $p$-values (Clogg, Petkova, and Haritou 1995).

Our approach is not without limitations. First, our use of cross-sectional data does not allow us to control for unobserved individual- or state-level characteristics that may affect mothers' employment. Studies examining mothers' labor force outcomes have often used panel data sets to account for this form of unobserved heterogeneity. Unfortunately, panel studies used for these purposes do not have large enough cell counts within states and by education level to use in our current application. Thus, our use of the ACS enables us to explore questions around state contexts that are unanswerable with existing, individual-level panel data sets. ${ }^{13}$ Applying longitudinal data would allow us to identify whether mothers' employment in states with expensive childcare increases once children enter school or whether the influence of state-level traditional gender norms weakens as children age. A second limitation pertains to the GSS data spanning multiple waves that are used to measure state gender norms. Although we take several steps to mitigate against potential bias introduced by pooling survey data across a wide time frame, it is still possible that our measure of gender norms is influenced by the span of years and, relatedly, by varying age groups represented across survey waves. Unfortunately, the GSS sample size for a single year is too small to produce reliable state-level estimates, thus requiring us to pool multiple survey waves. Although a strength of our approach is the use of established measures of gender norms in the GSS, it is possible that future research using alternative measures with larger within-state samples in a single year may expand and test our findings. Finally, we include a range of state-level controls to ensure that our measures of childcare costs and gender norms are robust to observed confounders. Nonetheless, additional measures across 
states or deeper investigations at lower geographical levels (e.g., cities, metropolitan areas, commuting districts) would strengthen our contributions. All these limitations point to important areas for future research.

\section{RESULTS}

\section{Descriptives}

Across states, an average of 38 percent of women in our sample had a preschool-age child (Table 2). This varied only slightly by level of education, with college-educated women being an average of three percentage points less likely to have a young child than women with lower levels of education. We observed larger educational differences in employment rates. Whereas an overall average of three-fourths of women were employed, only 59 percent of women with a high school diploma or less were employed compared with 86 percent of those with a college degree. Women without children were more likely to be employed than mothers regardless of education, but the gap was largest among the college educated: College-educated women without children were 15 percentage points more likely to be employed than collegeeducated mothers. For women whose highest level of education is a high school diploma, mothers are about nine percentage points less likely to be employed than women without children.

\section{[Table 2 About Here]}

Maternal employment rates range considerably from a low of 55 percent in Idaho to a high of 78 percent in South Dakota (see Online Appendix Figure A2). Across all states but Wyoming, college-educated mothers are more likely to work than mothers with a high school diploma or less. College-educated mothers are most likely to be employed in Vermont (90 percent) and least likely in Utah (58 percent), whereas less-educated mothers are most likely to 
work in Wyoming (83 percent) and least likely to work in New Mexico (44 percent). These differences suggest significant state variation in maternal employment by level of education.

Table 2 reports state childcare costs and gender norms. On average, the cost of childcare across U.S. states is nearly 12 percent of married couples' annual family income and ranges from a low of 7 percent in Louisiana to a high of 16 percent in Oregon. Gender norms around women's responsibility for childcare also vary by state: States such as West Virginia, Alabama, and Utah have more traditional norms, whereas other states such as New Jersey, Massachusetts, and Iowa have more egalitarian norms. Due to confidentiality restrictions in the sensitive geocoded GSS data, we are unable to report specific estimates for states' gender norms. General geographic variation in both norms and childcare costs, however, are illustrated in Figures 1 and 2. Descriptive trends indicate state variation in mothers' employment, childcare costs, and gender norms. These estimates also show important differences in employment rates between college-educated and less-educated mothers. To further investigate the relationship between these variables, we now examine predictors of mothers' employment.

\section{Predictors of Maternal Employment}

Baseline employment patterns by parental status. Table 3 reports coefficients for the marginal effects of motherhood and state contexts on women's probability of employment. The results were derived from three sets of stepwise models (represented by panels A, B, and C) conducted independently for the full sample, the sample of women with a high school or lower level of educational attainment, and the sample of college graduates. The first set (panel A in Table 3) establishes the baseline relationship of motherhood to employment conditional on individual- and state-level control variables. The marginal effects indicate that, among all 
women, mothers are 10.3 percentage points less likely to work than women without children $(p<$ 0.001). Consistent with the descriptives, the negative relationship of motherhood on employment is larger among the college educated, but significant and substantial across all levels of education. Coefficients representing the relationship of motherhood to the probability of employment are illustrated in the Online Appendix Figure A3. College-educated mothers are more than 13 percentage points less likely to work than college-educated women without children $(p<0.001)$, whereas mothers with a high school diploma or less are 6.6 percentage points less likely to be employed $(p<0.001)$.

\section{[Table 3 About Here]}

Childcare costs and maternal employment. The next set of models (panel B in Table 3) examines whether the probability of mothers' employment varies by state-level childcare costs and gender norms. Focusing on women without children in the pooled sample, we find that childcare costs are unrelated to employment, as expected. Turning to mothers, however, Table 3 reports that expensive childcare has a strong negative association with employment (support for H1). For the full sample, the coefficient indicates nearly a one-to-one relationship: A difference in childcare costs of one percentage point predicts a reduction in mothers' probability of employment by approximately 0.9 percentage points $(p<0.01)$. Comparing the marginal effects of childcare costs for mothers and non-mothers (equivalent to the coefficient for the interaction of motherhood and childcare costs) provides an estimate of how these state characteristics influence the employment gap between these groups. As reported in Table 3, not only are mothers less likely to be employed in states with expensive childcare, but the gap between mothers and non-mothers is also larger in these states $(p<0.001)$ (see Online Appendix Figure A4). 
The negative relationship between childcare costs and mothers' employment is most pronounced for mothers with lower levels of education, where the marginal effects of childcare costs increased by more than one-fifth compared with the full sample. Among mothers with a high school education, a difference of one percentage point in childcare costs as a share of family income predicts a 1.1 percentage point reduction in the probability of employment $(p<0.05)$. The motherhood employment penalty among women with lower levels of educational attainment is predicted to be more than 10 percentage points smaller and nonsignificant in states with the least expensive childcare (8 percent of income) compared with those where childcare costs reach 16 percent of family income (Online Appendix Figure A4).

For the college-educated sample, Table 3 shows that childcare costs are associated with increased probability of employment for women without children $(p<0.05)$, likely reflecting the association between childcare costs and favorable state economic conditions (see Landivar, Ruppanner, and Scarborough 2021). For college-educated mothers, expensive childcare is negatively related to the probability of employment $(p<0.05)$. Comparing the association of childcare costs with employment between mothers and non-mothers, we again find a significant relationship of childcare costs to the motherhood employment gap $(p<0.05)$, such that states with more expensive childcare have slightly larger differences in employment between collegeeducated mothers and women without children. The marginal change in the motherhood employment gap for the college educated is about 6.6 percentage points between the least and most expensive states (Online Appendix Figure A4-1).

Gender norms and mothers' employment. In addition to childcare costs, Table 3 also shows the relationship between state-level gender norms and women's employment. In general, egalitarian gender norms are associated with higher probabilities of employment across 
education level and for both mothers and non-mothers $(p<0.05$; support for H2). One exception is that the relationship between gender norms and employment among college-educated mothers is nonsignificant. However, the coefficient is positive and larger than that observed for collegeeducated non-mothers. Corresponding to the positive relationship of gender norms to employment across subsamples, we find that these state-level characteristics are not significantly related to the motherhood employment gap. This is illustrated in Online Appendix Figure A4-2, where the motherhood employment gap is only slightly smaller in egalitarian states compared with traditional ones. Collectively, these findings suggest that egalitarian gender norms improve women's probability of employment generally, but do not necessarily have direct implications for mothers' employment.

Interactions of childcare costs and gender norms on mothers' employment. The last set of models (panel C) in Table 3 report marginal effects on employment for the intersection of childcare costs and gender norms among both mothers and women without children. These results were calculated with a three-way interaction term including motherhood, childcare costs, and gender norms and provide insight on whether the relationship of childcare costs to mothers' employment varies across state-level gender norms. Results from the full sample reveal that the coefficient for the interaction of these state-level contexts is in opposite directions between nonmothers and mothers, but is significant only for non-mothers $(p<0.001)$. Nonetheless, the difference between these coefficients (equivalent to the coefficient for the three-way interaction) is significant $(p<0.001)$, indicating that the interaction of state childcare costs and gender norms has implications for the motherhood employment gap.

Figure $4 \mathrm{a}$ visualizes this interaction. Note that the plotted estimates are restricted in Figure 4 relative to previous visualizations because there were no states with very traditional 
gender norms where childcare costs exceeded an average of 14 percent of married couples' family income and only one state (South Dakota) with very egalitarian norms and childcare costs as low as 8.8 percent of family income. Figure $4 \mathrm{a}$ shows that the negative relationship of childcare costs to the motherhood employment gap is most severe when occurring alongside traditional gender norms (support for H3). In states with higher childcare costs where childcare consumes 14 percent of family income, mothers are predicted to be 9.4 percentage points less likely to work than non-mothers in states with egalitarian gender norms, and 17.2 percentage points less likely to work than non-mothers in traditional environments. In other words, the negative effects of expensive childcare on the motherhood employment gap is more than seven percentage points worse in states with traditional gender norms than in states with egalitarian norms. The relationship of gender norms to employment weakens in medium-cost states, with a marginal difference of about 3.7 percentage points between egalitarian and traditional environments, and it disappears in lower-cost childcare contexts where there is virtually no relationship between gender norms and mothers' employment.

[Figure 4 About Here]

These relationships are most pronounced among the college educated $(p<0.001)$ and nonsignificant for those with a high school diploma or lower level of education (support for H4). As illustrated in Figure 4b, the motherhood employment gap among the less educated varies by state-level childcare costs, but not by gender norms. In contrast, $4 \mathrm{c}$ illustrates that the interaction of childcare costs and gender norms has a strong relationship on the employment gap between college-educated mothers and non-mothers. For the highly educated, egalitarian gender norms reduce the negative effects of expensive childcare for college educated mothers. In states where childcare costs an average of 14 percent of family income, the maternal employment penalty 
associated with expensive childcare is almost twice as large in traditional environments as egalitarian ones.

The results reported in Table 3 and Figure 4 provide evidence that the moderating effects of gender norms on the relationship of childcare costs to mothers' employment is constrained primarily to those with higher levels of education, adding further theoretical nuance to the association of structural contexts and cultural environments. Among those with greater resources at their disposal (in this case, higher levels of education), gender norms play a larger role in shaping mothers' employment in environments with high childcare costs. For those with fewer resources, these norms play a much smaller role. Instead, the more influential state-level factor is the structural constraint of childcare costs.

As a further sensitivity test, we examined whether the patterns illustrated in Figure 4 varied by mothers' race and ethnicity. Our findings were consistent for White, Black, and Latina mothers and are illustrated in Online Appendix Figure A5. For all three groups, childcare costs are most detrimental to maternal employment in contexts with traditional gender norms. Importantly, the employment gap between mothers and non-mothers was largest among White women and smaller among Black and Latina women. Nonetheless, in high-cost traditional environments, mothers of all racial/ethnic groups are predicted to be 10 to 20 percentage points less likely to be employed than non-mothers.

\section{CONCLUSION}

Our results extend existing research showing that 1) mothers are less likely to be employed than women without children, and that 2) childcare expenses remain a major barrier to mothers' employment. Analyzing these relationships at the state level, we find that the 
association between maternal employment and childcare costs is strongest for women with lower levels of education.

In a novel contribution, we unpack how gender norms at the state level condition the relationship of childcare costs to mothers' employment. We show that college-educated mothers living in states with traditional gender norms are less likely to be employed than college educated mothers in more egalitarian states when childcare costs are high. These mothers may have a harder time justifying the cost of expensive childcare when prevailing cultural expectations make the decision to remain employed unpopular. These relationships are evident only for our college-educated sample, and have no association for mothers with lower levels of education. That traditional gender norms are more influential among college-educated mothers is perhaps unsurprising because intensive mothering norms are grounded in middle-class expectations of "good mothering" (Hays 1996). Here we show that these norms are more closely integrated into some state cultures than others, with consequences for college-educated mothers' employment. In line with previous research (Ruppanner 2020), we underscore that U.S. states vary in their prevailing cultural norms similar to the ways that countries do, such as those in the European Union; thus, treating the United States as a homogeneous or monolithic entity neglects the institutional and cultural barriers to mothers' employment. We also extend a robust crossnational literature showing that the intersection of resources, in this case childcare costs, and norms are critical for mothers' employment outcomes (Boeckmann, Misra, and Budig 2015; Budig, Misra, and Boeckmann 2012).

Our results show that college-educated mothers who face two institutional barriersexpensive childcare and traditional gender norms - are more likely to exit employment. By contrast, mothers in more egalitarian states with expensive childcare maintain employment. 
These results indicate a dynamic relationship between structural and cultural factors and maternal employment. Structural barriers related to childcare costs play a prominent role, particularly for those who have lower levels of education and fewer resources at their disposal. Among the highly educated, greater resources relate to increased employment only if supported by egalitarian gender norms. Broadly, these findings suggest that reducing structural barriers alone may not be enough to advance mothers' employment. Similar progress is needed in advancing egalitarian gender norms that support the equal participation of mothers and fathers in paid work and family life.

Ultimately our results are clear: Maternal employment suffers when childcare is expensive and gender norms traditional. We find the structural barrier of childcare costs is most impactful for less-educated mothers and that college-educated mothers have lower rates of employment when norms are traditional and childcare costs are high. As states look to develop policies to integrate mothers into employment, our research underscores the importance of structure and culture in shaping patterns of maternal employment. 


\section{NOTES}

${ }^{1}$ In addition to examining the interaction of state childcare costs and childcare norms by mothers' level of education, we follow existing literature that shows these relationships vary by race. Research has shown that intensive mothering norms are most acutely internalized by white mothers (Fox 2006). However, our analyses did not support this claim, rather showed similar patterns across race (Appendix Figure A5). This may reflect that we are examining norms as contextual features of states that shape expectations directed toward women more broadly, rather than internalized perspectives that influence individual-level decisions. We therefore direct our theoretical and empirical approach to differences by education.

${ }^{2}$ Childcare costs for infants and 4-year-olds are highly correlated, thus infant care costs are a reliable indicator of childcare pricing differences across states.

${ }^{3}$ Information on state childcare costs was missing for all states in 2016 and for Nebraska, Rhode Island, and Texas in 2013. We calculated average childcare costs from 2013 through 2017 excluding these missing cases. In supplementary analyses, we imputed missing information by taking the mean of adjacent years. Our findings remain consistent when using these imputed values.

${ }^{4}$ These data come from the GSS Sensitive data sets which provide geocoded information on respondents. GSS Sensitive Data files were obtained under special contractual arrangements designed to protect the anonymity of respondents. These data are not available from the authors. Persons interested in obtaining GSS Sensitive Data Files should contact the GSS at GSS@NORC.org. 
${ }^{5}$ Another variable from the GSS commonly used in studies of gender norms and attitudes measures respondents' support for women in politics (the FEPOL variable). We do not use this variable in our measure of gender norms because prior research has shown it reflects a separate dimension of gender norms pertaining to leadership (Scarborough and Sin 2020) and our focus is on norms about motherhood and families. Furthermore, factor analysis revealed that the FEPOL variable did not load well with the three selected items in Table 1. Based on both established practices in the literature and our empirical factor analysis, we decided to omit FEPOL from the measurement of gender norms and instead use the three items measuring gender norms toward the family, which had higher levels of internal reliability.

${ }^{6}$ On the measure of gender norms, Kansas had an extreme value that was 1.5 times the interquartile range from the third quartile, thus qualifying it as an outlier (Schwertman, Owens, and Adams 2004). In addition, respondents from this state had, on average, high levels of influence on model results, as measured with Pregibon's delta beta (Pregibon 1981), which was over four times larger than the average among states included in the study, and leverage, which surpassed the recommended cutoff of $2(k-1) / n$ (Gordon 2012).

${ }^{7}$ For those not employed, we predicted hourly earnings based on age, age squared, race, education, and state of residence. The resulting estimate provides a measure of lost wages for respondents who are outside the labor force.

${ }^{8}$ Those without a spouse had a value of zero on this variable.

${ }^{9}$ We benchmark Head Start enrollment against the population of three- and four-year-olds in poverty because these children are highly likely to qualify for Head Start 
${ }^{10} 2016$ was the most recent year available for information on the share of eligible families receiving childcare subsidies.

${ }^{11}$ As a further robustness check, we also included state-level controls for managerial intensity (percent of workers in management) and state median wage, but these were highly correlated ( $r>$ 0.8) with the percent college educated. Their inclusion did not affect our substantive results and thus are excluded.

${ }^{12}$ All substantive findings are consistent when using logistic regression models to calculate log odds, odds ratios, or average marginal effects.

${ }^{13}$ To account for the limitations of the ACS related to unobserved confounders, our research design of comparing mothers to non-mothers provides a counterfactual whereby each group would be similarly affected by unobserved confounders, but only mothers' employment should be associated with childcare costs. This approach has been validated in other research on mothers' employment and childcare costs using cross-sectional data (Landivar, Ruppanner, and Scarborough 2021). 


\section{REFERENCES}

Acker, Joan. 1990. Hierarchies, jobs, bodies: A theory of gendered organizations. Gender \& Society 4 (2): 139-58.

Blackburn, McKinley L., David E. Bloom, and David Neumark. 1993. Fertility timing, wages, and human capital. Journal of Population Economics 6 (1): 1-30.

Blair-Loy, Mary. 2003. Competing devotions: Career and family among women executives. Cambridge, MA: Harvard University Press.

Blau, David, and Erdal Tekin. 2007. The determinants and consequences of child care subsidies for single mothers in the USA. Journal of Population Economics 20 (4): 719-41.

Boeckmann, Irene, Joya Misra, and Michelle J. Budig. 2015. Cultural and institutional factors shaping mothers' employment and working hours in postindustrial countries. Social Forces 93 (4): 1301-33.

Breen, Richard. Kristian Bernt Karlson, and Anders Holm. 2018. Interpreting and understanding logits, probits, and other nonlinear probability models. Annual Review of Sociology 44: $39-54$.

Budig, Michelle J., Joya Misra, and Irene Boeckmann. 2012. The motherhood penalty in crossnational perspective: The importance of work-family policies and cultural attitudes. Social Politics: International Studies in Gender, State \& Society 19 (2): 163-93.

Charles, Kerwin Kofi, Jonathan Guryan, and Jessica Pan. 2018. The effects of sexism on American women: The role of norms vs. discrimination. Working Paper 24904. Working Paper Series. Cambridge, MA: National Bureau of Economic Research.

Chaudry, Ajay, Taryn Morrissey, Christina Weiland, and Hirokazu Yoshikawa. 2017. Cradle to kindergarten: A new plan to combat inequality. New York: Russell Sage Foundation. 
Child Care Aware of America. 2013-2017. Annual State Fact Sheets. https://www.childcareaware.org/our-issues/research/statefactsheets/

Clogg, Clifford C., Eva Petkova, and Adamantios Haritou. 1995. Statistical methods for comparing regression coefficients between models. American Journal of Sociology 100 (5): 1261-93.

Collins, Caitlyn. 2019. Making motherhood work: How women manage careers and caregiving. Princeton, NJ: Princeton University Press.

Collins, Caitlyn. 2020. Who to blame and how to solve it: Mothers' perceptions of work-family conflict across western policy regimes. Journal of Marriage and Family 82 (3): 849-74.

Collins, Patricia Hill. 1994. Shifting the center: Race, class, and feminist theorizing about motherhood. In Mothering: Ideology, experience, and agency, edited by Evelyn Nakano Glenn, Grace Chang, and Linda Rennie Forcey. New York: Routledge.

Collins, Patricia Hill. 2000. Black feminist thought: Knowledge, consciousness, and the politics of empowerment. 2nd Edition. New York: Routledge.

Connelly, Rachel, and Jean Kimmel. 2003. Marital status and full-time/part-time work status in child care choices. Applied Economics 35 (7): 761-77.

Correll, Shelley J., Ridgeway, Cecilia L., Zuckerman, Ezra W., Sharon Jank, Sara Jordan-Bloch, and Sandra Nakagawa. 2017. It's the conventional thought that counts: How third-order inference produces status advantage. American Sociological Review 82 (2): 297-327.

Cotter, David, Joan M. Hermsen, and Reeve Vanneman. 2011. The end of the gender revolution? Gender role attitudes from 1977 to 2008. American Journal of Sociology 117 (1): 25989.

Damaske, Sarah. 2011. For the Family? How class and gender shape women's work. Oxford, UK: Oxford University Press. 
Dean, Paul, Kris Marsh, and Bart Landry. 2013. Cultural contradiction or integration? Workfamily schemas of Black middle class mothers. In Notions of family: Intersectional perspectives, edited by Marla H. Kohlman, Dana B. Krieg, and Bette J. Dickerson. Bingley, UK: Emerald Group.

Dernberger, Brittany N., and Joanna R. Pepin. 2020. Gender flexibility, but not equality: Young adults' division of labor preferences. Sociological Science 7: 36-56.

Dow, Dawn Marie. 2019. Mothering while Black: Boundaries and burdens of middle-class parenthood. Oakland, CA: University of California Press.

Ferguson, Roderick A. 2003. Aberrations in black: Toward a queer of color critique. Minneapolis: University of Minnesota Press.

Fox, Bonnie. 2006. Motherhood as a class act: The many ways in which "intensive mothering" is entangled with social class. In Social reproduction: Feminist political economic challenges neo-liberalism, edited by Kate Bezanson and Meg Luxton. Montreal, Canada: McGill-Queen's.

Friedman-Krauss, Allison H., W. Steven Barnett, G.G. Weisenfeld, Richard Kasmin, Nicole DiCrecchio, Michelle Horowitz. 2018. The State of Preschool 2017. New Brunswick, NJ: National Institute for Early Education Research.

Gordon, Rachel A. 2012. Applied statistics for the social and health sciences. New York: Routledge.

Gross, Christi L., Brianna Turgeon, Tiffany Taylor, and Kasey Lansberry. 2014. State intervention in intensive mothering: Neo-liberalism, new paternalism and poor mothers in Ohio. In Intensive mothering: The cultural contradictions of modern motherhood, edited by Linda Rose Ennis. Bradford, ON, Canada: Demeter Press. 
Hays, Sharon. 1996. The cultural contradictions of motherhood. New Haven, CT: Yale University Press.

Hook, Jennifer L., and Eunjeong Paek. 2020. National family policies and mothers' employment: How earnings inequality shapes policy effects across and within countries. American Sociological Review 85 (3): 381-416.

Ishizuka, Patrick. 2019. Social class, gender, and contemporary parenting standards in the United States: Evidence from a national survey experiment. Social Forces 98 (1): 31-58.

Jacobs, Jerry A., and Kathleen Gerson. 2016. Unpacking Americans' views of the employment of mothers and fathers using national vignette survey data: SWS presidential address. Gender \& Society 30 (3): 413-41.

Kaufman, Gayle. 2020. Fixing parental leave: The six month solution. New York: NYU Press. Kids Count Data Center. 2021. Head Start enrollment by age group in the United States. https://datacenter.kidscount.org/data/tables/9786-head-start-enrollment-by-age-group

Knight, Carly R., and Mary C. Brinton. 2017. One egalitarianism or several? Two decades of gender-role attitude change in Europe. American Journal of Sociology 122 (5): 14851532.

Lamar, Margaret R., Lisa K. Forbes, and Laura A. Capasso. 2019. Helping working mothers face the challenges of an intensive mothering culture. Journal of Mental Health Counseling 41 (3): 203-20.

Landivar, Liana Christin. 2017. Mothers at work: Who opts out? Boulder, CO: Lynne Rienner.

Landivar, Liana Christin, Leah Ruppanner, and William J. Scarborough. 2021. Are states created equal? Moving to a more expensive childcare state reduces mothers' odds of employment. Demography 58 (2): 451-70. 
Laughlin, Lynda. 2013. Who's minding the kids? Child care arrangements: Spring 2011. Current Population Reports. Washington, DC: U.S. Census Bureau. https://www.census.gov/prod/2013pubs/p70-135.pdf

Long, J. Scott, and Sarah A. Mustillo. 2018. Using predictions and marginal effects to compare groups in regression models for binary outcomes. Sociological Methods \& Research, October 21. https://doi.org/10.1177/0049124118799374.

National Institute for Early Education Research. 2021. State of Preschool Yearbook. https://nieer.org/state-preschool-yearbooks.

Padamsee, Tasleem J. 2009. Culture in connection: Re-contextualizing ideational processes in the analysis of policy development. Social Politics: International Studies in Gender, State \& Society 16 (4): 413-45.

Pearse, Rebecca, and Raewyn Connell. 2016. Gender norms and the economy: Insights from social research. Feminist Economics 22 (1): 30-53.

Pfau-Effinger, Birgit. 2012. Women's employment in the institutional and cultural context. International Journal of Sociology and Social Policy 32 (9/10): 530-43.

Pregibon, Daryl. 1981. Logistic regression diagnostics. Annals of Statistics 9 (4): 705-24.

Ruggles, Steven, Sarah Flood, Ronald Goeken, Josiah Grover, Erin Meyer, Jose Pacas, and Matthew Sobek. 2020. IPUMS USA: Version 10.0 [data set]. Minneapolis, MN: IPUMS. https://doi.org/10.18128/D010.V10.0

Ruppanner, Leah. 2020. Motherlands: How states in the U.S. push mothers out of employment. Philadelphia, PA: Temple University Press.

Ruppanner, Leah, and David J. Maume. 2016. The state of domestic affairs: Housework, gender and state-level institutional logics. Social Science Research 60: 15-28. 
Ruppanner, Leah, Stephanie Moller, and Liana Sayer. 2019. Expensive childcare and short school days $=$ lower maternal employment and more time in childcare? Evidence from the American Time Use survey. Socius 5 (January). https://doi.org/10.1177/2378023119860277.

Scarborough, William J., Caitlyn Collins, Leah Ruppanner, and Liana Christin Landivar. 2021. Head Start and families' recovery from economic recession: Policy recommendations for COVID-19. Family Relations 70 (1): 26-42.

Scarborough, William J., and Ray Sin. 2020. Gendered places: The dimensions of local gender norms across the United States. Gender \& Society 34 (5): 705-35.

Scarborough, William J., Ray Sin, and Barbara Risman. 2019. Attitudes and the stalled gender revolution: Egalitarianism, traditionalism, and ambivalence from 1977 through 2016. Gender \& Society 33 (2): 173-200.

Schwertman, Neil C, Margaret Ann Owens, and Robiah Adnan. 2004. A simple more general boxplot method for identifying outliers. Computational Statistics \& Data Analysis 47 (1): $165-74$.

Stone, Pamela. 2007. Opting out? Why women really quit careers and head home. Berkeley: University of California Press.

Tekin, Erdal. 2007. Single mothers working at night: Standard work, child care subsidies, and implications for reform. Economic Inquiry 45 (2): 233-50.

Ullrich, Rebecca, Stephanie Schmit, and Ruth Cosse. 2019. Inequitable access to child care subsidies. Washington, DC: The Center for Law and Social Policy.

U.S. Bureau of Labor Statistics. 2021. Employment characteristics of families summary. https://www.bls.gov/news.release/famee.nr0.htm. 
U.S. Department of Health and Human Services. 2015. Child Care and Development Fund (CCDF) Program, Proposed Rule, 80 Fed. Reg. 80466-80582. Issued December 24. https://www.federalregister.gov/documents/2015/12/24/2015-31883/child-care-anddevelopment-fund-ccdf-program

Women's Bureau, U.S. Department of Labor. 2020. Women in the labor force: Labor force participation rate of mothers by age of youngest child. https://www.dol.gov/agencies/wb/data/facts-over-time/women-in-the-labor-force\#laborforce-participation-rate-of-mothers-by-age-of-youngest-child. 


\section{TABLES}

\section{TABLE 1: Items from General Social Survey Used to Calculate State Gender Norms}

Description Response options

Tell me if you agree or disagree with this statement:

1. It is much better for everyone involved if the

Strongly Agree, Agree, Disagree, Strongly man is the achiever outside the home and the Disagree woman takes care of the home and family.

2. A working mother can establish just as warm and secure a relationship with her children as a mother who does not work.

3. A preschool child is likely to suffer if his or her mother works.

Strongly Agree, Agree, Disagree, Strongly

Disagree

Strongly Agree, Agree, Disagree, Strongly Disagree 
TABLE 2: State-Level Descriptives

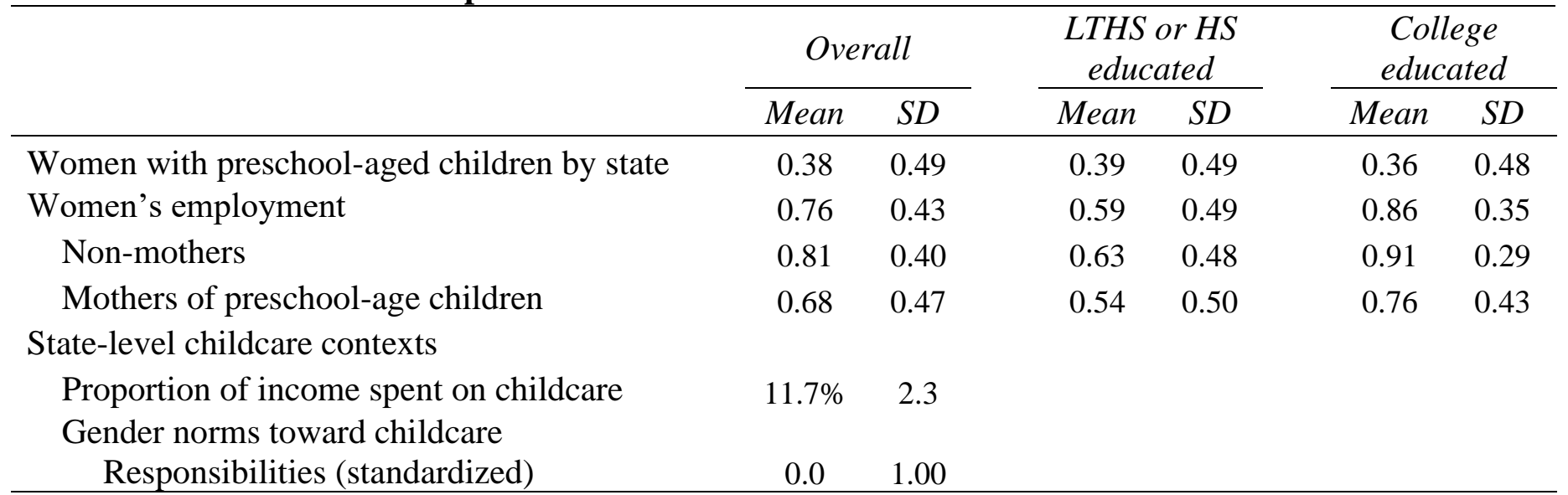

NOTE: LTHS, less than high school; SD, standard deviation. 


\begin{tabular}{|c|c|c|c|c|}
\hline & Full Sample & $\begin{array}{c}\text { Iigh school \& } \\
\text { LTHS }\end{array}$ & College & $\begin{array}{c}\text { Sig. diff ( } \mathrm{p}< \\
0.05), \text { high } \\
\text { school/ LTHS } \\
\text { vs. College? }\end{array}$ \\
\hline \multicolumn{5}{|l|}{ A. Baseline } \\
\hline Motherhood & $-0.103 * * *$ & $-0.066 * * *$ & $-0.132 * * *$ & Yes \\
\hline \multicolumn{5}{|l|}{ B. Motherhood*state contexts } \\
\hline \multicolumn{5}{|l|}{ Childcare costs } \\
\hline Non-mothers & 0.0017 & 0.0018 & $0.002 *$ & No \\
\hline Mothers & $-0.009 * *$ & $-0.011 *$ & $-0.006^{*}$ & No \\
\hline Difference, mothers-non mothers & $-0.011 * * *$ & $-0.013 * *$ & $-0.008 *$ & Yes \\
\hline \multicolumn{5}{|l|}{ Egalitarian gender norms } \\
\hline Non-mothers & $0.013 * * *$ & $0.017 * *$ & $0.006^{*}$ & No \\
\hline Mothers & $0.026 * *$ & $0.024 *$ & $0.021 \dagger$ & No \\
\hline Difference, mothers/non-mothers & 0.013 & 0.007 & 0.015 & No \\
\hline \multicolumn{5}{|l|}{ C. Childcare cost ${ }^{*}$ norms } \\
\hline Non-Mothers & $-0.005 * * *$ & $-0.005^{*}$ & $-0.003 * * *$ & No \\
\hline Mothers & $0.006 \dagger$ & -0.0003 & $0.009 * *$ & No \\
\hline Difference, mothers/non-mothers & $0.010 * * *$ & -0.006 & $0.012 * * *$ & Yes \\
\hline
\end{tabular}

NOTE: LTHS, less than high school. Models A, B, and C were conducted in stepwise linear probability models with individual and state-level control variables. Individual-level covariates include race, education (for pooled models), marital status, age, age squared, foreign-born status, logged hourly earnings (predicted for those not employed), and logged spousal income. State covariates include casualization, industry composition, unemployment rate, percent college educated, logged population, racial composition, percent foreign born, ratio of Head Start enrollment to children in poverty, percent of three- and four-year-olds in statefunded pre-K, and the share of eligible families receiving CCDBG (Child Care and Development Block Grant) childcare subsidies. Models include varying intercept and slope for motherhood. Coefficients for the differences between mothers and non-mothers are equivalent to the coefficient for the interaction term between motherhood and the respective predictors.

$\dagger p<0.1, * p<0.05, * * p<0.01, * * * p<0.001$. 


\section{FIGURES}

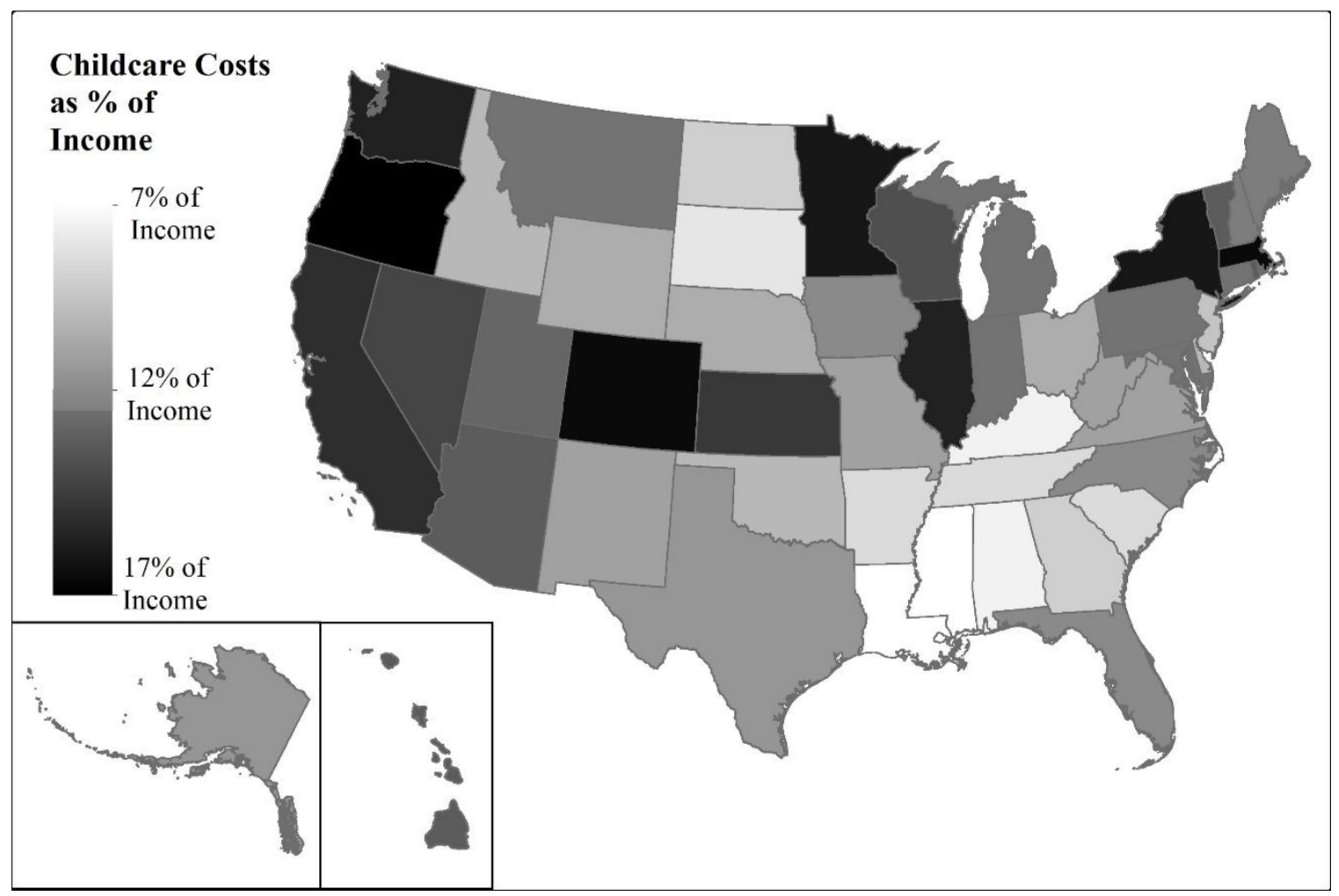

FIGURE 1: State Variation in Childcare Costs

NOTE: Childcare costs are measured as the cost of full-time, center-based childcare for infants as a percent of median family income for married couples in each state. Information for this measure come from the Child Care Aware State Factsheets averaged across 2013-2017. 


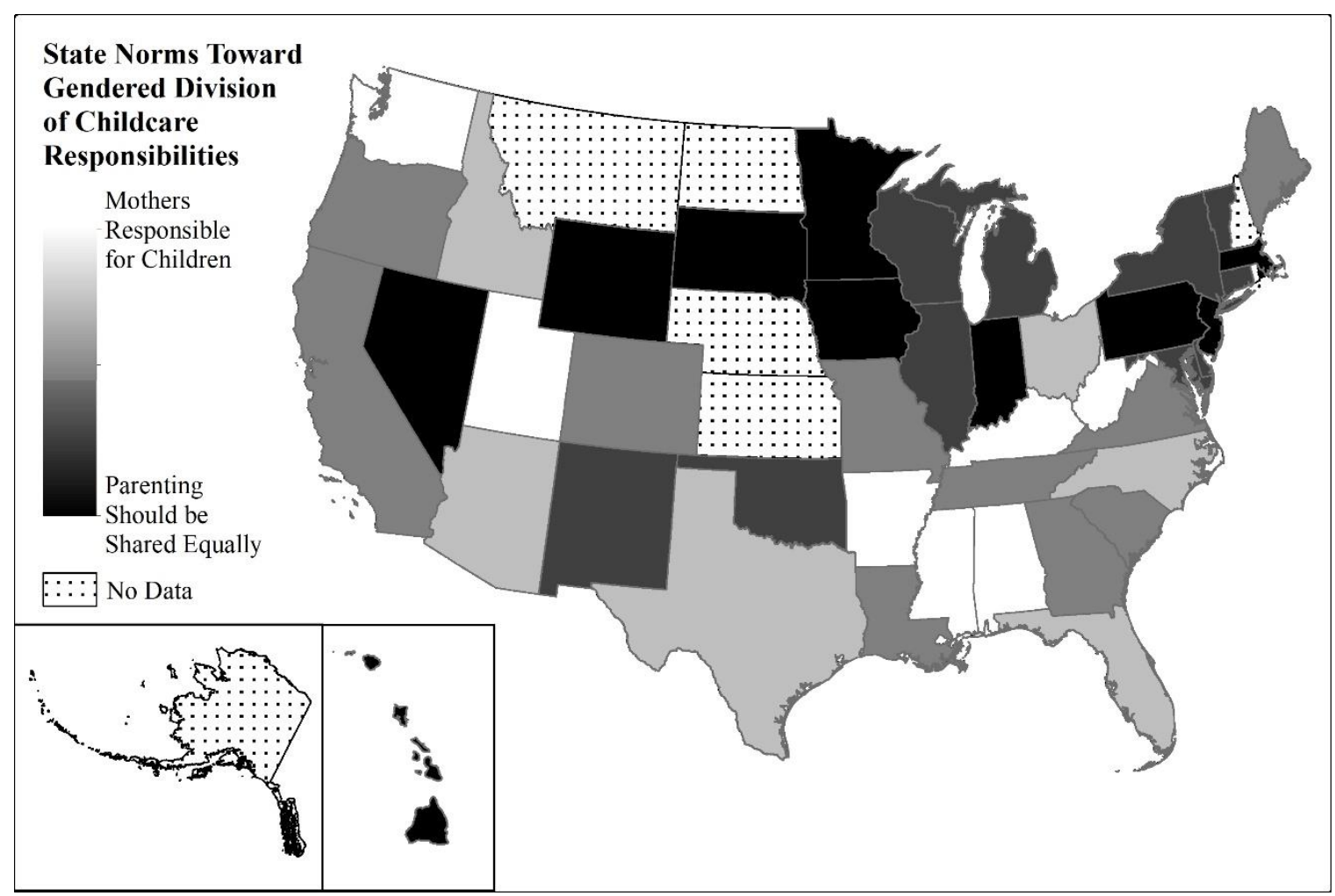

FIGURE 2: State Variation in Gender Norms

NOTE: Gender norms were calculated with data from the General Social Survey, years 2000 through 2018, using the average response to three attitudinal items reported in Table 1. Gender norm estimates are micro-adjusted for respondent gender, race, education, age, and survey year. States with fewer than 50 respondents were recoded as missing. Further details are reported in the section on data and variables. 


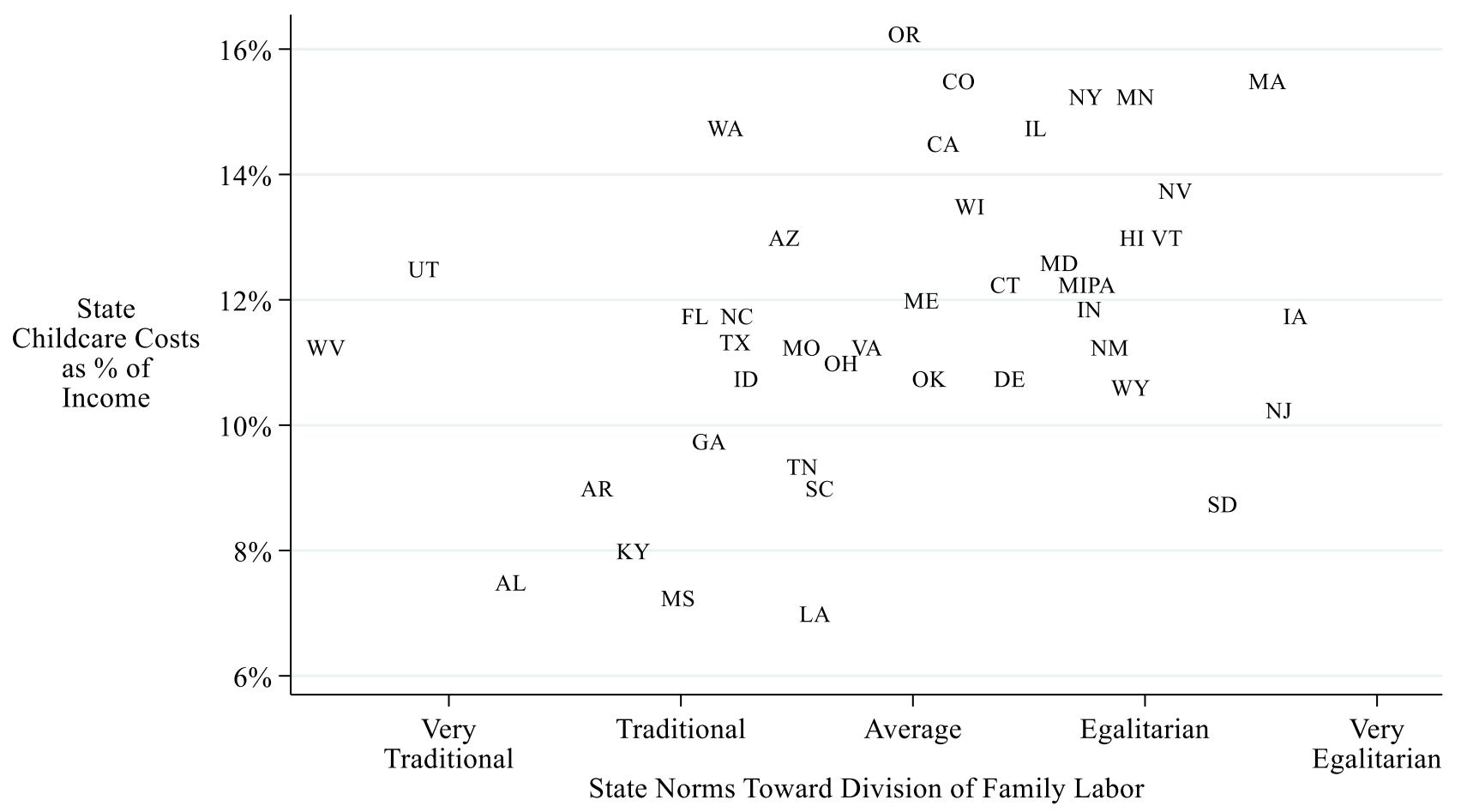

\section{FIGURE 3: State Childcare Costs by Gender Norms}

NOTE: Childcare costs are measured as the cost of full-time, center-based childcare for infants as a percent of median family income for married couples in each state. Information for this measure come from the Child Care Aware State Factsheets averaged across 2013-2017. Gender norms calculated with data from the General Social Survey, years 2000 through 2018, using the average response to three attitudinal items reported in Table 1. Gender norm estimates are adjusted for respondent gender, race, education, age, and survey year. States with fewer than 50 respondents were recoded as missing. 
4a. Full Sample

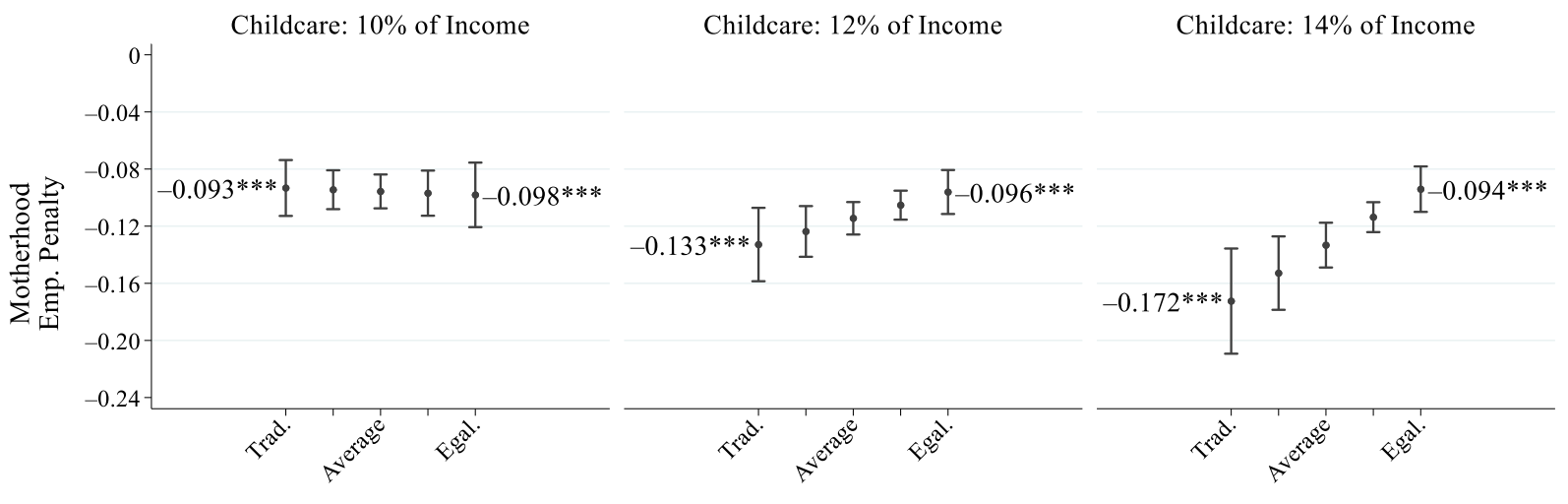

State Gender Norms

4b. High School / Less Than High School

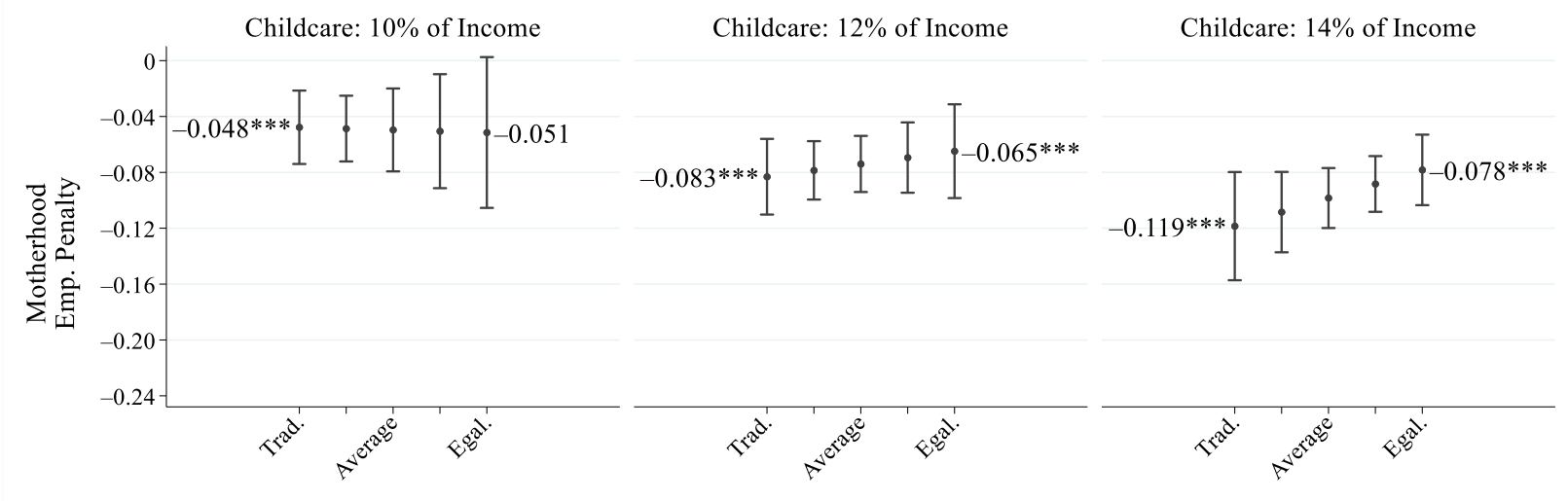

State Gender Norms

4c. College Educated

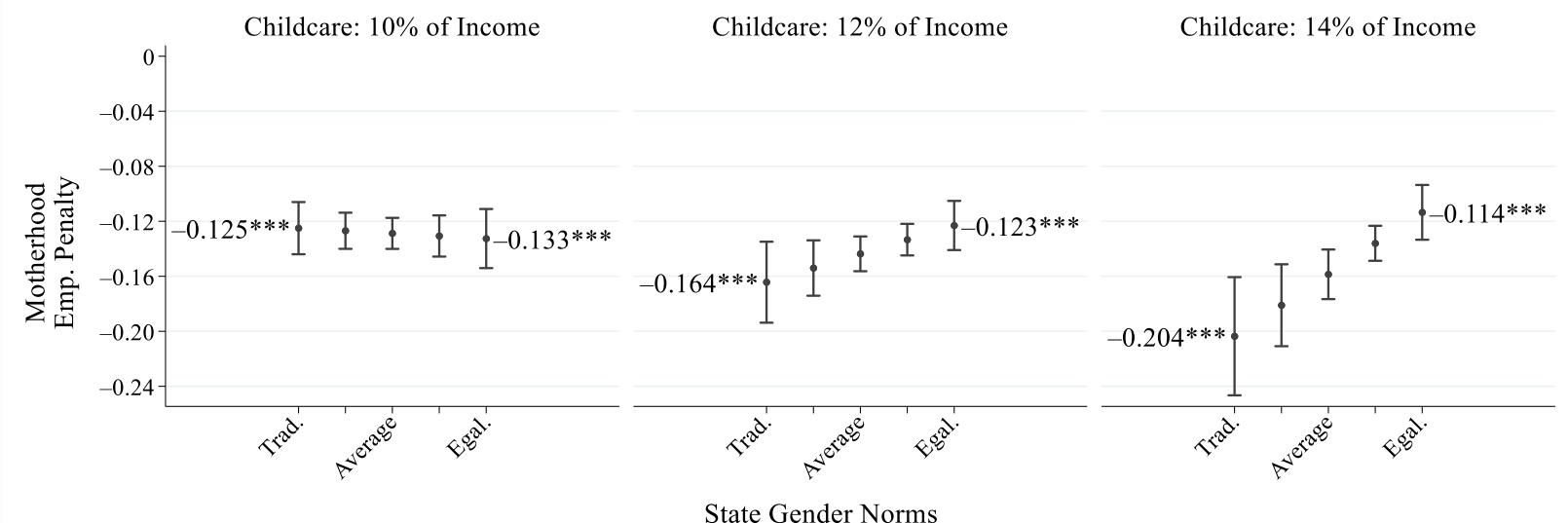

FIGURE 4: Motherhood Penalty on Employment by Interaction of State Childcare Costs and Gender Norms

NOTE: Dots represent point estimates for the effect of motherhood on the probability of employment.

Vertical lines represent $95 \%$ confidence intervals. Significance levels: $* p<0.05, * * p<0.01, * * * p<0.001$. 


\section{ONLINE APPENDIX}

\section{One Child}

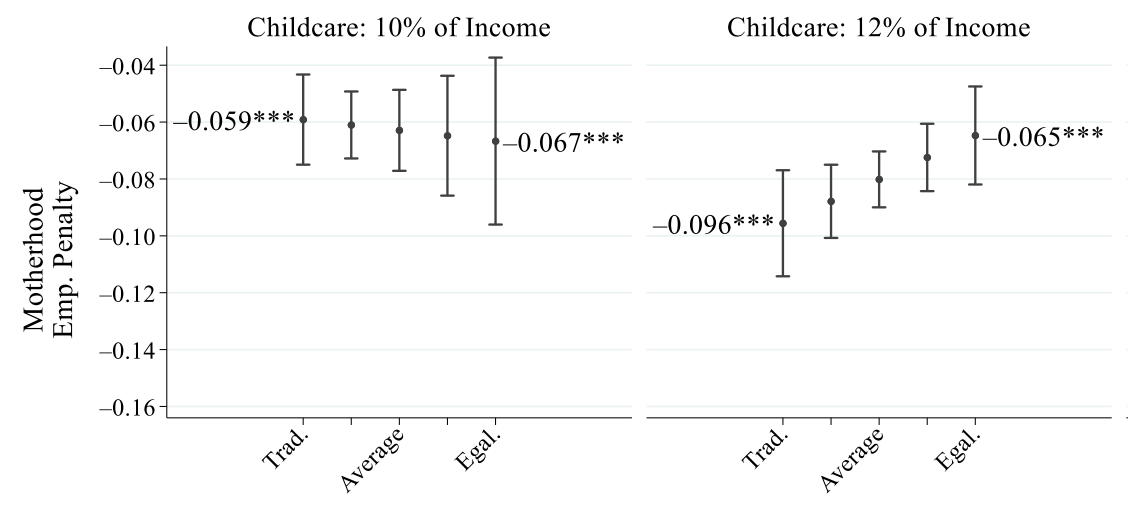

Childcare: $14 \%$ of Income

State Gender Norms

\section{Two Children}

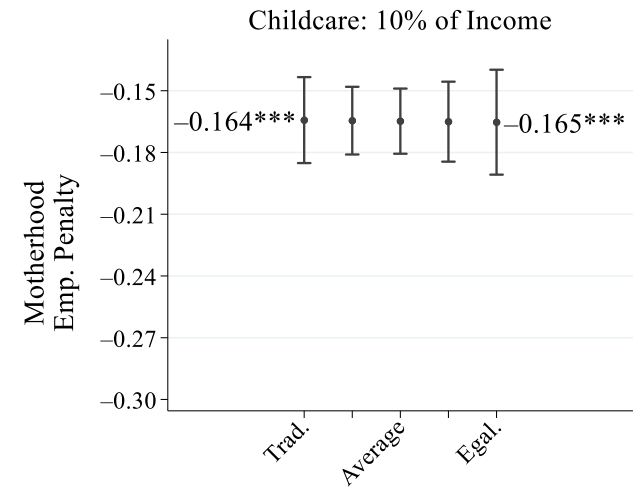

Childcare: $12 \%$ of Income
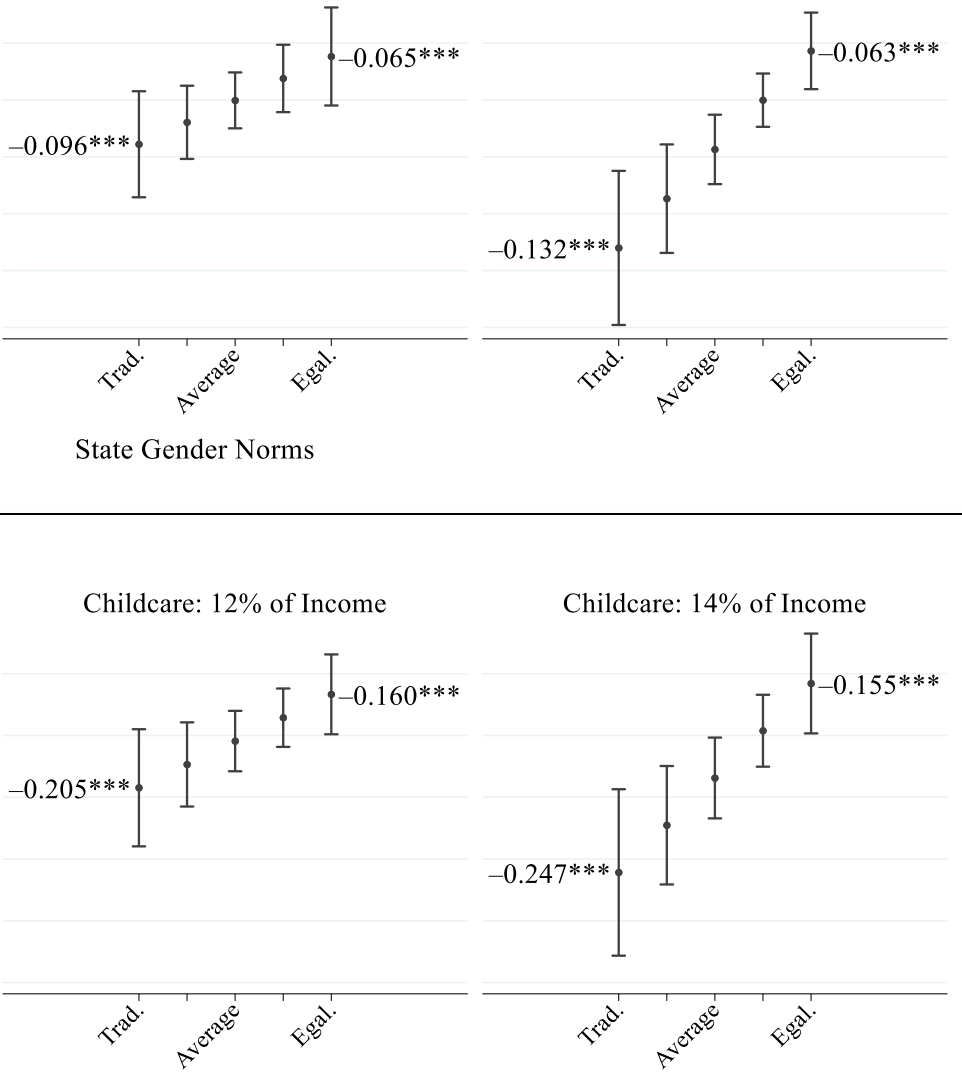

State Gender Norms

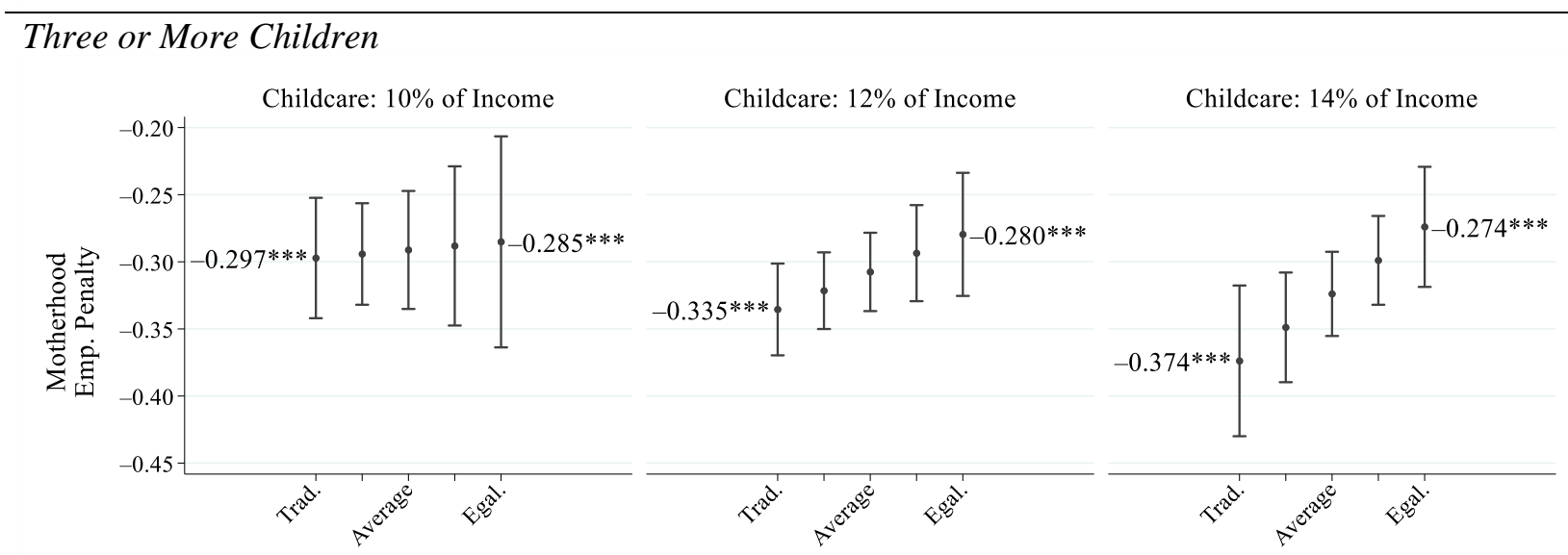

State Gender Norms 


\section{FIGURE A1: Motherhood Penalty on Employment by Interaction of State Childcare Costs and}

\section{Gender Norms by Number of Children}

NOTES: Dots represent point estimates for the effect of motherhood on the probability of employment. Vertical lines represent $95 \%$ confidence intervals. Significance levels: ${ }^{*} p<0.05,{ }^{* *} p<0.01, * * * p<0.001$. Figure A1 reports the coefficients for motherhood on the probability of employment for mothers with one, two, and three or more children across state-level childcare costs and gender norms. We calculated the results reported in Figure A1 with the same models presented in the main text, Figure 4, but we replaced the dichotomous variable for motherhood with a categorical variable indicating non-mothers, mothers of one child, mothers of two children, and mothers of three or more children. We present findings corresponding to the fully interactive model for the interrelationship of childcare costs and gender norms (corresponding to Figure $4 \mathrm{a}$ for the full sample in the main text). 


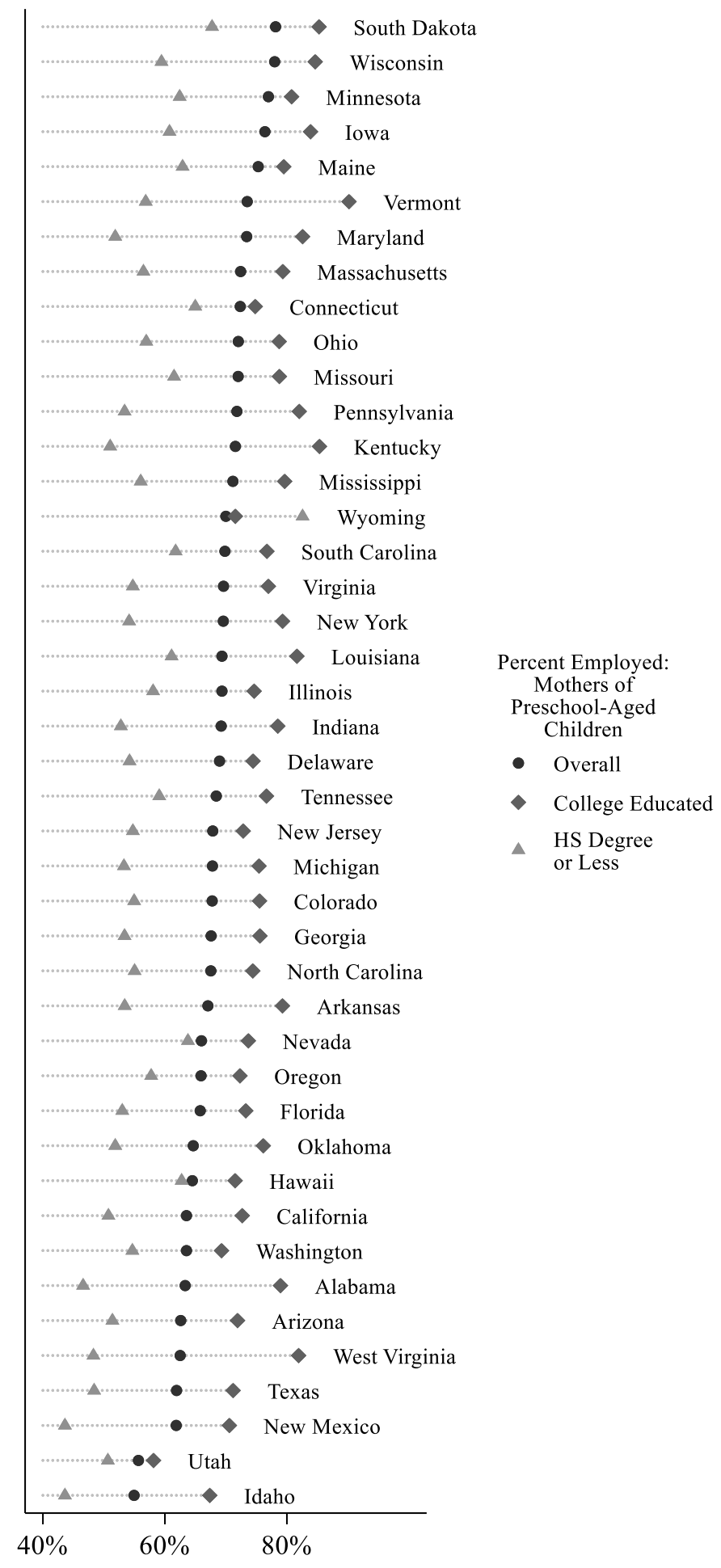

FIGURE A2: Rates of Maternal Employment by State and Mothers' Education

Source: 2017 American Community Survey. 


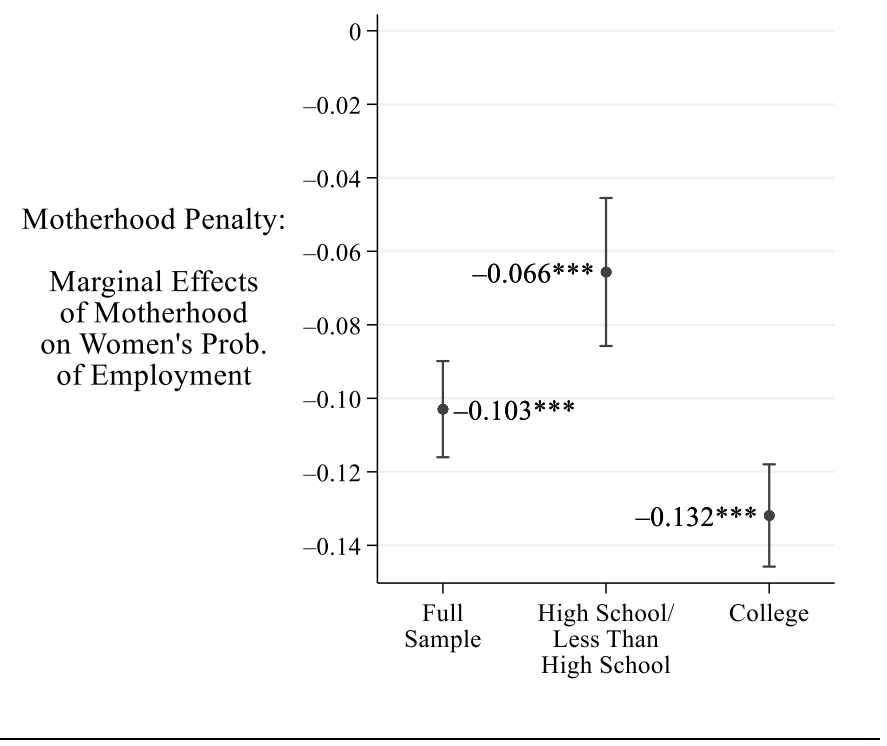

FIGURE A3: Predicted Effects of Motherhood on Women's Probability of Employment 
A4-1. Employment Penalty by Childcare Costs
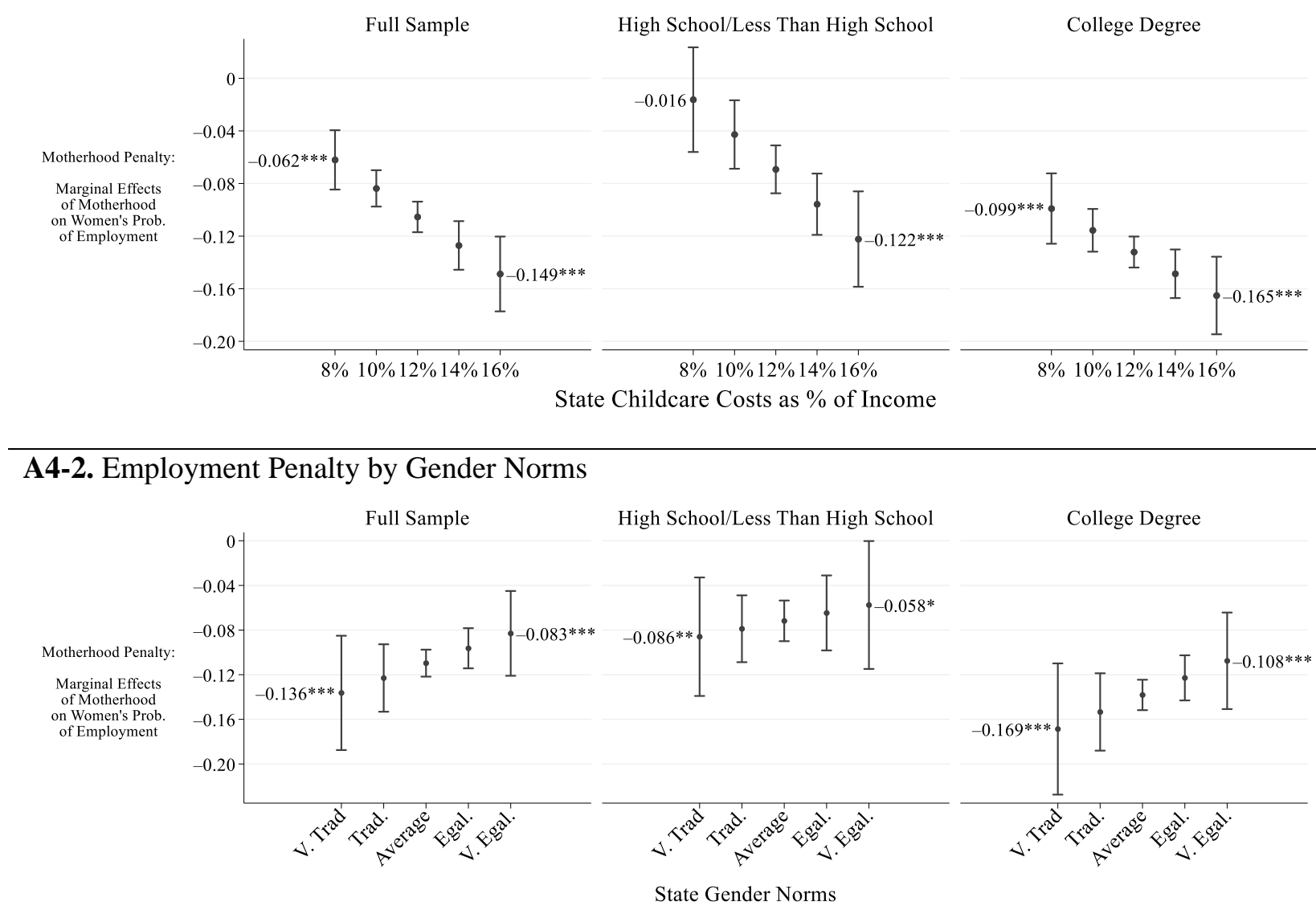

FIGURE A4: Motherhood Penalty on Employment by State Context

NOTE: Dots represent point estimates for the effect of motherhood on the probability of employment. Vertical lines represent $95 \%$ confidence intervals. Significance levels: $* p<0.05, * * \mathrm{p}<0.01, * * * p<0.001$. 
White Respondents

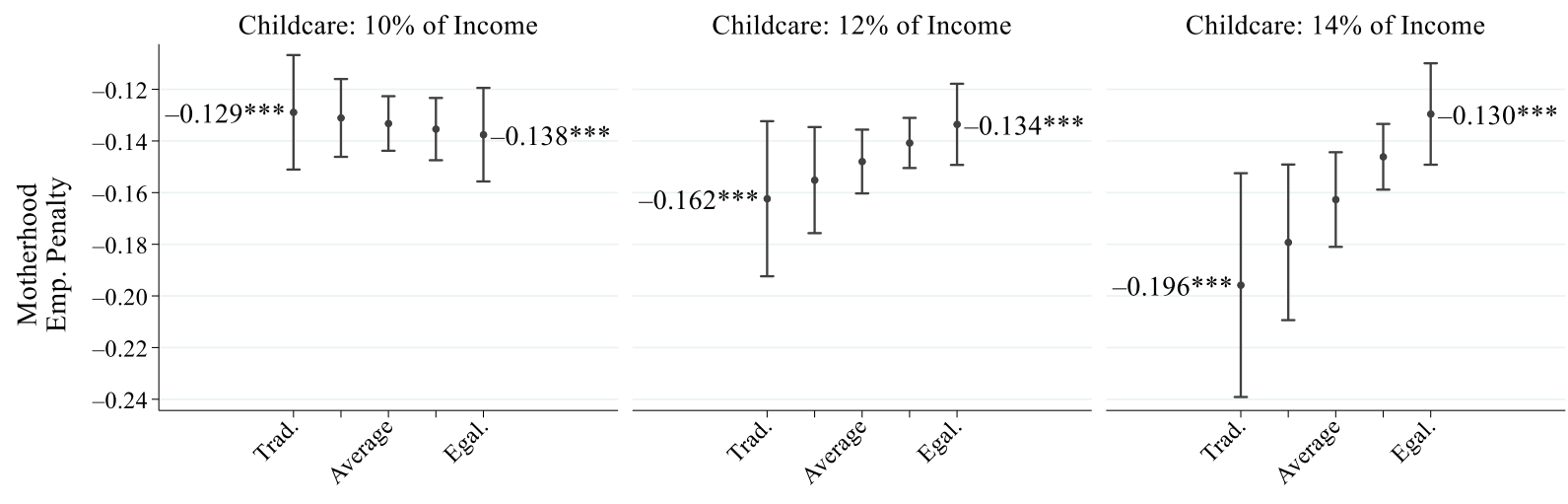

State Gender Norms

\section{Black Respondents}

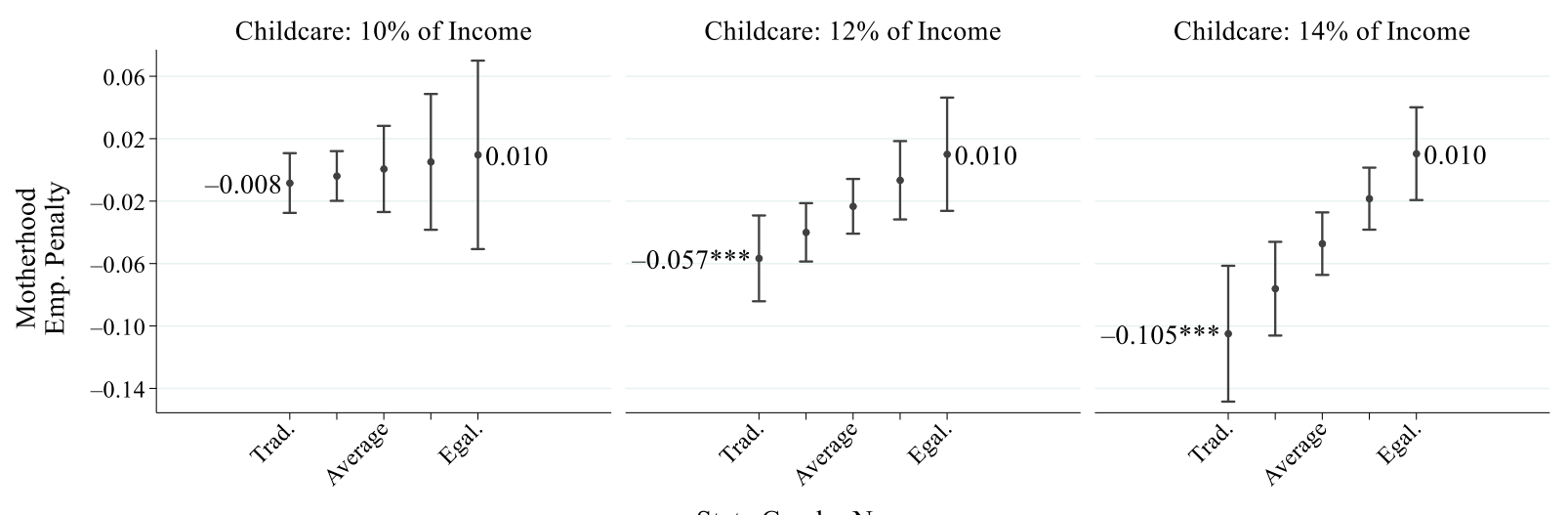

State Gender Norms

Latina Respondents

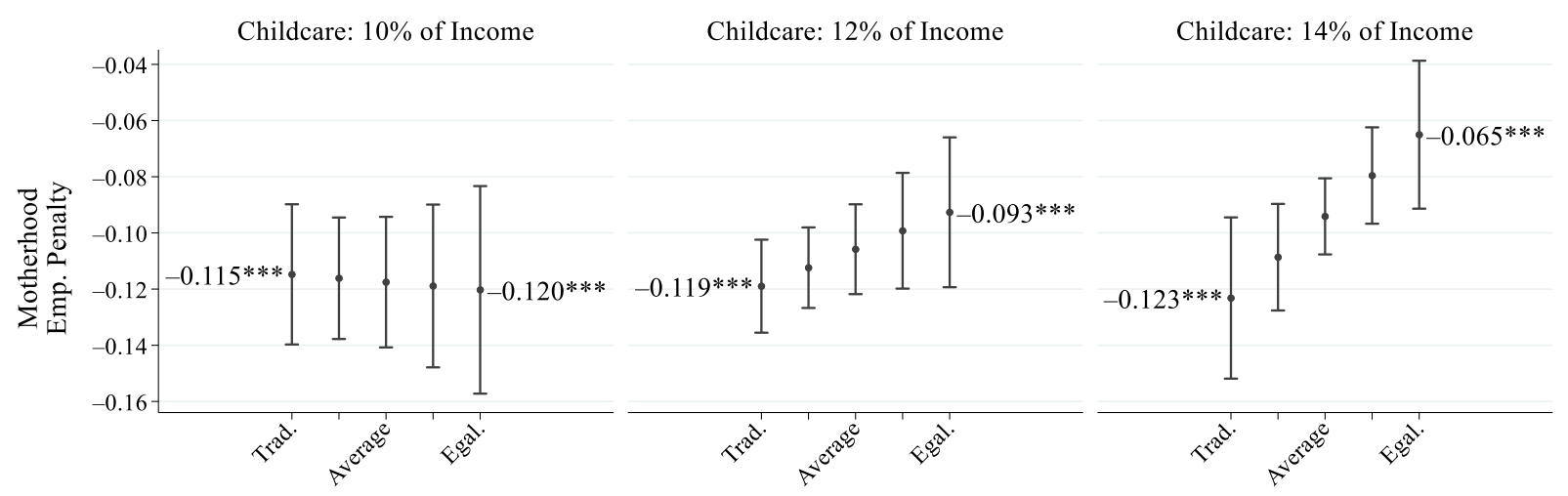

State Gender Norms

FIGURE A5: Motherhood Penalty on Employment by Interaction of State Childcare Costs and Gender Norms by Race 
NOTES: Dots represent point estimates for the effect of motherhood on the probability of employment.

Vertical lines represent $95 \%$ confidence intervals. Significance levels: ${ }^{*} p<0.05,{ }^{* *} p<0.01,{ }^{* * *} p<0.001$. In Figure A5, we report results from sensitivity tests examining whether the results presented in Figure 4 from the main text are consistent across race. In these models, we use the same equations corresponding to Figure 4 for the full sample, but apply it independently to samples of White, Black, and Latina respondents. The intersection of childcare costs and gender norms has similar effects across race, although relative levels of maternal employment are higher for Black and Latina mothers. Additionally, Figure A5 shows one perplexing result where Latina mothers are more likely to be employed in high-cost states with egalitarian norms than low-cost states with egalitarian norms, although this difference was not significant. One reason for this pattern could be that the limited number of low-cost states with egalitarian norms (such as South Dakota and Wyoming) have a small population of Latina residents, making estimates less precise. 